\title{
What should be Included in an International Agriculture Undergraduate Course?
}

\author{
Thomas Bruening \\ Associate Professor \\ Agricultural and Extension Education Department \\ 335 Agricultural Administration Building \\ The Pennsylvania State Univeristy \\ University Park, PA, 16802 \\ E-mail: Tbruening@psu.edu \\ Xiaorong Shao \\ Research Associate \\ Agricultural and Extension Education Department \\ 415 Agricultural Administration Building \\ The Pennsylvania State Univeristy \\ University Park, PA, 16802 \\ E-mail: xzs100@psu.edu
}

\begin{abstract}
The purpose of this study was to identify the topics and teaching methods appropriate in a beginning international agriculture undergraduate course. A three round Delphi procedure was used to solicit expert opinions regarding important topics and effective teaching methods to deliver an international agriculture course for U.S. undergraduate students. The results revealed that the highest rated topics needed to be included in the international agriculture course were: role of agriculture in economic development; globalization and the implications/affect on agriculture; the role of culture in agricultural international development; definition of a developing country and a developed country; why a world-view is important to today's agricultural producers and leaders; and agricultural extension and education systems in different countries. The top five teaching methods suggested by the panel of experts included experiential learning; presentations and dialog with those who have worked long term in relevant countries; field studies/trips to view various agricultural practices (one-three weeks); internships; and field trips to a country. Educators might consider the directions provided by this panel of experts when they develop coursework in international agriculture.
\end{abstract}

Keywords: Internationalized Curriculum, Undergraduate Education, International Agriculture Course, International Topics, Teaching Methods 


\section{Background}

It has become increasingly obvious to many scholars and administrators, and also to business communities within universities, there is a need to be more engaged in international education. Some suggest that higher education should completely reform the curriculum to include more global content somewhat like the changes that took place within the writing across the curriculum movement.

Frequently, internationalization of the curriculum is referred to as a process of preparing students to work in an increasingly interdependent world. Maidstone (1995) suggested that the rationale to integrate global topics and themes in higher education included the following four points: globalization of the curriculum needs to take place because of the emergence of a worldwide political economy, greater interdependency among nations, changes in international security, and demographic changes in society (Maidstone, 1995). Still others believed that internationalization of the curriculum is a required part of the students' undergraduate experience. Maidstone (1995, p. 7) stated, "The realization before us now is that the question is not whether international/intercultural education should be a significant part of our colleges; without it what we call 'education' is incomplete and insufficient for our contemporary and future needs."

Recently a Harvard University

curricular review suggested that a significant emphasis now should be placed on internationalization of the curriculum. Harvard University, a leader in international education, with nearly $60 \%$ of senior students participating in international programs as part of their college experience, is now stressing the need for more internationalization of the curriculum. Platt (2004) in a review of the proposed changes indicated that Harvard University needed significant reforms so that undergraduates leave with a greater international knowledge and experience and stronger foreign language skills. Part of the rationale for increased international study is that today one in six U.S. jobs is directly tied to international trade. Ultimately, we need graduates who are globally competent so they can work expertly in other cultures and countries (Platt, 2004). According to Acker $\&$ Scanes (2000), multinational companies want to hire graduates who have crosscultural experiences and language skills. Moreover, most scholars believed that the understanding of diversity gained through international experiences helps students bridge the cultural gap.

Colleges of agriculture in particular have struggled to involve students directly in international study abroad programs.

According to the Chronicle of Higher Education (2000), only about one percent of students that studied abroad in the 1999 school year were agriculture students. Given the importance of food production systems in developing countries, and the need for cultural knowledge and global contextual understanding, it is surprising that the number of agricultural students participating in study abroad programs is not much higher (Bruening \& Frick, 2004).

\section{What is an internationalized curriculum? \\ Adding relevant international examples in coursework represents the first level of student academic international awareness. Stand-alone international courses provide students with a wide range of learning opportunities. Students who study abroad suggest a greater commitment of students to international learning. However to many, a fully actualized internationalized curriculum means that students should demonstrate a positive attitude toward other cultures, understand and articulate the}


interrelationship between countries, and possess the ability to work effectively in a global setting.

What is internationalized

curriculum? How is it defined? Bremer and van der Wende (1995) defined internationalized curriculum as: "Curricula with an international orientation in content, aimed at preparing students for performing (professionally/socially) in an international and multicultural context, and designed for domestic students and/or foreign students" (p. 10). This is a general description of suggested international content. What specific topics should be included in the curriculum to provide students with the knowledge needed to be effective in international agriculture? What are the most pressing topics that all students studying international agriculture should learn? What are the most important strategies to teach these concepts to students? What activities would best help students learn about international agriculture?

\section{Purpose and Objectives}

The purpose of this study was to identify the topics and teaching methods appropriate in a beginning international agriculture undergraduate course. The objectives of this paper were to:

1. describe the topics which need to be included in an international agriculture course;

2. identify the most effective teaching methods to deliver international agriculture content; and

3. propose the essential topics and teaching methods for faculty to consider when developing international programs and activities in agriculture.

\section{Methods, Procedures and Instrumentation}

The Delphi procedure is designed for the systematic solicitation of expert opinion. There are three characteristics that distinguish it from interpersonal group interaction: anonymity, iteration with controlled feedback, and statistical group response (Martino, 1983). This method is based on a structured process for collecting and distilling knowledge from a group of experts by means of a series of questionnaires interspersed with controlled opinion feedback (Adler \& Ziglio, 1996). It represents a useful communication device among a group of experts and thus facilitates the formation of a group judgment. This method has been widely used to generate forecasts in technology, education, and other fields (Dunham, 1996).

The Delphi method used in this study consisted of three rounds. Sixty professionals with extensive experiences in international agriculture from the membership list of Association for International Agricultural and Extension Education were identified to participate in this study (AIAEE, 2003). In the first round, a survey with open-ended questions that solicited topics and teaching methods in international agriculture curriculum was sent to the panel of 60 members. Twenty-eight individuals responded to the first round. The second round questionnaire was developed based upon the responses obtained from the first round, in which the respondents were asked to rate the topics and teaching methods for a 15-week introductory international agriculture course. Twentythree people returned the second round survey. After analysis, the items with a mean score of three or higher were selected to form the third and final round of surveys. In the final round, individual surveys were prepared for each panelist, and the respondents were given the opportunity to 
re-evaluate and change their original answers from the round two when comparing to the group means for each item. There were twenty-three responses to the final round.

A four-point Likert scale was used in the questionnaires for round two and three. They were: $4=$ very important, $3=$ important, $2=$ somewhat important, and $1=$ not important. "Don't know" and "Not applicable" were also used in the questionnaires.

Data were analyzed using Statistical Package for Social Sciences. The means and standard deviations were computed to summarize the data.

\section{Results/Findings}

In an open-ended question survey for the first round, the panel members were asked to identify four to seven most important topics that they believed undergraduate students should study in an introductory international agriculture course. They were also asked to propose three to five of the most effective teaching methods to deliver an international agriculture course.

Round one of the survey generated 97 topics and 63 teaching methods to deliver international agricultural curriculum. The 97 topics reflected a wide range of interests from gender to social, economic, culture, technology, extension, rural poverty and health dimensions.

The 97 topics and 63 teaching methods captured from the round one formed the round two survey, in which the participants were asked to rate each item on a Likert scale (1-4) according to its degree of perceived importance.

After analyzing the responses from round two, 50 topics and 41 teaching methods with a mean value of three or higher were selected to form the third and final round of this survey. In round three, the participants were asked to confirm their responses from round two.

\section{Topics in International Agriculture Curriculum}

Table 1 and Table 2 present the results from the third and final round. All items selected had mean values of 3.30 or higher. Table 1 contains the means, standard deviations, and rank of the topics suggested by the respondents that should be included in an international agriculture course.

The item "Role of agriculture in economic development" $(M=3.61)$ had the highest mean value among 16 highest rated topics, followed by the item "Globalization and the implications/affect on agriculture" $(M=3.57)$. The items "The role of culture in agricultural international development" and "Definition of a developing country and a developed country" had the same mean value of 3.52. Two items that were ranked fifth were "Agricultural extension and education systems in different countries" and "Why a world-view is important to today's agricultural producers and leaders" $(M=3.48)$.

The panel members placed an emphasis on the culture as three items among the 16 highest rated topics dealt with the cultural issues. These items were "The role of culture in agricultural international development" $(M=3.52)$; "Cultural perspectives on GMOs, pesticide use, etc." $(M=3.30)$ and "Understanding and appreciation of cultural differences between one's own culture and contrasting cultures" $(M=3.43)$. In addition, the term globalization and its impact as well as implications on agricultural development were also frequently mentioned by the respondents. 
Table 1

Highest Rated International Agricultural Topics

Topic

Role of agriculture in economic development

$\begin{array}{cccc}n & M & S D \text { Rank } \\ 23 & 3.61 & .58 & 1\end{array}$

Globalization and the implications/affect on agriculture

$\begin{array}{llll}23 & 3.57 & .66 & 2\end{array}$

The role of culture in agricultural international development

$\begin{array}{llll}23 & 3.52 & .59 & 3\end{array}$

Definition of a developing country and a developed country

$\begin{array}{llll}23 & 3.52 & .67 & 3\end{array}$

Agricultural extension and education systems in different countries

$\begin{array}{llll}23 & 3.48 & .59 & 5\end{array}$

Why a world-view is important to today's agricultural producers and

$\begin{array}{llll}23 & 3.48 & .67 & 5\end{array}$

leaders

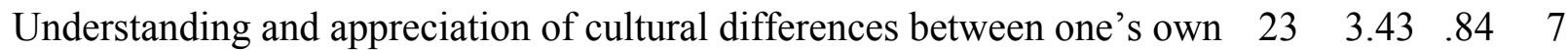

culture and contrasting cultures

Definition of development: our own agricultural development and aiding $\quad 23 \quad 3.39 \quad 66 \quad 8$

the development of other nations

Agricultural development approaches in developing countries

$\begin{array}{llll}23 & 3.39 & .78 & 8\end{array}$

Importance of agricultural development and training role of extension

$\begin{array}{llll}23 & 3.35 & .71 & 10\end{array}$

field workers

Contemporary issues impacting agriculture globally (i.e. GMO's)

Strategies affecting the relative success of agricultural development

$\begin{array}{llll}23 & 3.35 & .65 & 10\end{array}$

projects

Women in agriculture (especially in developing countries)

$\begin{array}{llll}23 & 3.30 & .64 & 12\end{array}$

Participatory and rapid rural appraisal methods and techniques with field experience

Globalization: how the current system works and how markets for

$\begin{array}{llll}23 & 3.30 & .56 & 12\end{array}$

$\begin{array}{llll}23 & 3.30 & .64 & 12\end{array}$

agricultural commodities fit the big picture of globalization

Cultural perspectives on GMOs, pesticide use, etc.

$\begin{array}{llll}23 & 3.30 & .70 & 12\end{array}$

Note. $M \geq 3.30$. Scale: $4=$ very important, $3=$ important, $2=$ somewhat important, and $1=$ not important.

\section{Teaching Methods in International} Agriculture Curriculum

Table 2 presents the means, standard deviations, and rank regarding teaching methods proposed by the respondents to deliver an international agriculture course.

Two items "Experiential learning" and "Presentations and dialog with those who have worked long term in relevant countries" were rated as the most effective methods to teach international agriculture curriculum. These two items had a mean value of 3.61 and were the top rated teaching methods. The item "Field studies/trips to view various agricultural practices (one-three weeks)" $(M=3.60)$ was rated as the third most effective teaching method. The fourth and fifth items in the ranking were "Internship" $(M=3.57)$ and "Field trip in a country" $(M=3.55)$. 
Table 2

Highest Rated International Agriculture Teaching Methods

\begin{tabular}{|c|c|c|c|c|}
\hline Teaching Method & $n$ & $M$ & $S D$ & Rank \\
\hline Experiential learning & 23 & 3.61 & .58 & 1 \\
\hline $\begin{array}{l}\text { Presentations and dialog with those who have worked long term in } \\
\text { relevant countries }\end{array}$ & 23 & 3.61 & .72 & 1 \\
\hline Field studies/trips to view various agricultural practices (one-three weeks) & 20 & 3.60 & .68 & 3 \\
\hline Internships & 21 & 3.57 & .60 & 4 \\
\hline Field trip in a country & 22 & 3.55 & .74 & 5 \\
\hline $\begin{array}{l}\text { Case study exercises where students must assume a different way of } \\
\text { thinking }\end{array}$ & 23 & 3.52 & .51 & 6 \\
\hline Attending international conferences such as AIAEE & 22 & 3.50 & .67 & 7 \\
\hline $\begin{array}{l}\text { Case studies of various international agriculture settings (must be } \\
\text { inclusive of different types of agricultural systems }\end{array}$ & 23 & 3.48 & .67 & 8 \\
\hline Faculty exchange program (a week to 4 month) & 21 & 3.48 & .75 & 8 \\
\hline Current event discussions & 22 & 3.45 & .86 & 10 \\
\hline Study abroad (one month-one semester program) & 20 & 3.45 & .76 & 10 \\
\hline Presentations and dialog with people from relevant countries & 23 & 3.43 & .73 & 12 \\
\hline Student exchanges (short-term reciprocal) & 21 & 3.43 & .75 & 12 \\
\hline $\begin{array}{l}\text { Student group activities, including nominal group process, collaborative } \\
\text { projects, etc. }\end{array}$ & 22 & 3.41 & .85 & 14 \\
\hline $\begin{array}{l}\text { Debate/discussion on current issues in world agriculture where each } \\
\text { student represents a country selected during the course }\end{array}$ & 23 & 3.35 & .78 & 15 \\
\hline $\begin{array}{l}\text { Presentations or panels of international agriculture. Leaders or graduate } \\
\text { students who are experienced professionals in agriculture from other } \\
\text { countries }\end{array}$ & 23 & 3.35 & .83 & 15 \\
\hline $\begin{array}{l}\text { Readings/materials/websites that permit students to experience points of } \\
\text { view from another country concerning an agricultural issue }\end{array}$ & 23 & 3.30 & .77 & 17 \\
\hline
\end{tabular}

Note. $M \geq 3.30$. Scale: $4=$ very important, $3=$ important, $2=$ somewhat important, and $1=$ not important.

\section{Discussion}

The direction that the panel of experts provided helps the profession identify important topics that could be taught in an introductory international agriculture course. Key topics included economic development, globalization, knowledge of culture, and definitions of development. Variations of these four themes can also be found in several of the other sixteen topics. The development of extension and training is also an important topic. Developing the students' world view, information regarding the impact of GMO's, womens' role in international agriculture and participatory methods complete the list of topics. While these topics are wideranging and may not fit a single course, these suggested topics initiate and invite a dialogue of what it means to be a globally educated person in an introductory international agricultural course.

Four out of the top five rated international teaching methods focused on direct active learning of students in international settings. The top rated methods 
were internships, field trips, and study abroad. The panel of experts believed that these types of experiences enhance learning far beyond the traditional lecture methods that tend to dominate delivery techniques used in higher education. The second ranked item was information that students could obtain from people who worked for long periods of time in relevant foreign settings.

One national strategy on international education presented by the American Council on Education called for the increase of study and internships abroad. This study indicated that study abroad greatly enhances students' foreign language abilities, cross-cultural skills, and understanding of other cultures. Study abroad is also considered as an essential experiential component of international education (ACE, 2002). Acker and Scanes (2000) indicated that study abroad in a nonEnglish speaking environment provides valuable ways for students to gain experiences they need to make progress in seeing how others live, work, and learn.

Given the strong recommendations from so many sources, it is somewhat surprising that this panel of experts collectively rated short-term faculty exchanges higher than student study abroad short and long-term programs. Perhaps this is an indication that the panel perceived that faculty really need to leave the country before they are qualified to teach about international agriculture. Engberg and Green (2002) noticed that the commitment of the university presidents and senior leaders in international education is necessary, but insufficient to achieve the major changes needed in higher education. The curriculum change is the domain of the faculty. Higher education institutions need to provide opportunities for faculty to travel in order to conduct research, meet with colleagues, or accompany students. Once the faculty has developed firsthand international experiences, their interest and enthusiasm could grow and literately enhance international curriculum development as well as student study abroad. Furthermore, perhaps the limited support given by international biased faculty for student study abroad begins to explain why student participation in study abroad is so low. If these internationally oriented educators only rank study abroad at a ten then it is perhaps more understandable why so few colleges of agriculture students study abroad.

Various case studies methods were also highly rated teaching methods. In addition, attendance at international conferences such as the AIAEE conference was a highly ranked method. The focus of the most highly ranked items was on direct and active student learning experiences.

\section{Implications}

Clearly the dialogue within higher education has been toward more inclusion of global issues and topics. In agriculture, there are numerous unique opportunities to teach about the impact of globalization within a dynamic context. Food and fiber systems remain critical problems throughout the world. Food security and poverty impact more than a billion people on a daily basis. Increasing relevance is being placed on the threats of terrorism to food systems in and out of the U.S. These are major world problems that directly impact colleges of agriculture and the expertise of its faculty. Faculty should seize the opportunity to develop relevant courses that teach students how to solve these problems in an active way. The direction provided by this panel of experts can lead to the development of coursework that could have an impact on the inclusion of important global topics and teaching methods used in colleges of agriculture. 


\section{References}

Acker, D., \& Scanes C. G. (2000). A case for globalizing undergraduate education and student learning at colleges of agriculture. Journal of International Agricultural and Extension Education, 7(1), 47-51.

Adler, M., \& Ziglio, E (1996). Gazing into the oracle: The Delphi method and its application to social policy and public health (eds.). London: Jessica Kingsley Publishers.

American Council on Education (ACE), Center for Institutional and International Initiatives (2002). Beyond September 11: A comprehensive national policy on international education. Retrieved October 28, 2004, from http://www.acenet.edu/bookstore/pdf /2002 beyond 911.pdf

Association of International Agricultural Extension and Education (AIAEE) (2003). The membership list of the 19th AIAEE annual conference. May 2003, North Carolina.

Bremer, L., \& van der Wende, M. (1995). Internationalizing the Curriculum in Higher Education. The Hague: Nuffic.

Bruening, T. H., \& Frick, M. (2004).Globalizing the undergraduate experience: A case study of impact of an international filed-based course. Journal of International Agricultural and Extension Education, 11(1), 89-96.
Dunham, R. B. (1996). The Delphi technique. Retrieved December 3, 2004, from http://www.medsch.wisc.edu/admin med/2001/orgbehav/delphi.pdf

Engberg, D., \& Green, M. F. (2002). Promising practices: Spotlighting excellence in comprehensive internationalization. Center for Institutional and International Initiatives, American Council on Education. Retrieved October 28, 2004, from

http://www.acenet.edu/bookstore/pdf /2002_promising-practices.pdf

Maidstone, P. (1995). International literacy: A paradigm for change: A manual for internationalizing the curriculum. Victoria, BC: Centre for Curriculum, Transfer and Technology.

Martino, J. (1983). Technological forecasting for decision making. New York: Elsevier Science Publishing Company.

Platt, N. (2004) Make global skills a top priority. USA Edition of the Financial Times Limited. London, England.

The Chronicle of Higher Education (2000). Snapshot of report on study abroad programs. Retrieved January 8, 2003, from http://chronical.com/cgi2bin/printable.cgi?article $=$ http 